\title{
CHANGES AND DETERMINANTS IN UNDER-FIVE MORTALITY RATE IN TURKEY SINCE 1988
}

\author{
S. Songül Yalçın' ${ }^{1}$ Başak Tezel ${ }^{2}$, Mehmet Rıfat Köse ${ }^{2}$, Deniz Tugay ${ }^{3}$, Salih Mollahaliloğlư ${ }^{3}$, Yasin Erkoç ${ }^{4}$ \\ ${ }^{1}$ Unit of Social Pediatrics, Department of Pediatrics, Hacettepe University Faculty of Medicine, Ankara, Turkey \\ ${ }^{2}$ General Directorate of Maternal Child Health and Family Planning, Ministry of Health, Ankara, Turkey \\ ${ }^{3}$ School of Public Health, Refik Saydam Hygiene Center Presidency, Ankara, Turkey \\ ${ }^{4}$ Ministry of Health, Ankara, Turkey
}

\begin{abstract}
SUMMARY
Child survival is the focus of the fourth Millenium Developmental Goal (MDG4). This paper describes levels, trends, and differentials in Under-Five Mortality Rate (U5MR) and also summarizes state programmes in Turkey between 1988 and 2010. Turkey is among only a few countries that have already surpassed MDG4 and have reduced their under-five mortality rate by more than two-thirds. In 2010, 13 out of every 1,000 children died before their fifth birthday. Low birth weight, high-birth order, short birth intervals, rural residence, low level of maternal education and lowest wealth quintile have affected negatively children's chances of survival. Expanding the scope of free vaccination programmes for children, improving screening and disease prevention schemes aimed at children, encouraging breastfeeding, implementing an emergency obstetric care programme, improving the services provided to newborns (a newborn intensive care programme) have brought about a significant decrease in the rate of infant and under-five mortality. The implementation of state and region specific action plans should be necessary to increase the chance of an access to the Continuum of Care for each mother and infant and to surpass MDG4.
\end{abstract}

Key words: children, mortality rates, millennium, developmental goals, Turkey

Address for correspondence: S. Yalçın, Unit of Social Pediatrics, Department of Child Health and Diseases, Hacettepe University Faculty of Medicine, 06100 Ankara, Turkey. E-mail: siyalcin@hacettepe.edu.tr

\section{INTRODUCTION}

Within the ten Millennium Development Goals (MDGs), child survival is the focus of the fourth MDG, that calls for a two-thirds reduction in under-five mortality rate (U5MR - the number of children dying before the age of 5 per 1,000 live births) between 1990 and 2015 (1). Turkey is among only a few countries that have already surpassed MDG4 and have reduced their U5MR by more than two-thirds (2-5). As many countries are undergoing rapid social and economic changes, Turkey provides an interesting case study for this decline.

To decrease U5MR, a continuum of care for mothers, newborns and children that integrate programmes for reproductive health, safe motherhood, newborn care, and child survival, growth and development should be provided appropriately. The concept of the continuum of care has arisen in recent years from the recognition that an integrated approach reaps more dividends than myriad of separate initiatives (6). Country profiles could be easily followed by elements of the continuum of care (7). The purpose of this report is to review the changes in U5MR, infant mortality rate (IMR) and neonatal mortality rate (NMR) in Turkey since 1988, with the current statistics and to summarize state interventions and status of the continuum of care in Turkey. Further, country status was compared with OECD (the Organisation for Economic Cooperation and Development) countries, WHO (the World Health Organisation) regions, UNPOP (the United Nations Population
Division) region, and UNICEF (the United Nations Children's Fund) regions.

\section{METHODS}

The data is taken from the national cross-sectional demographic and health surveys (TDHS) conducted in Turkey between 1988 and 2008 (8-12). TDHS collects nationally representative data on women of child-bearing age (15-49 years) and their children. Changes in prevalence of mortality between surveys were given as percentages. These studies included variables of children born in the 5 years preceding the survey. Data of the Turkish Ministry of Health, the Turkish Statistical Institute (TURKSTAT), the Turkish Health Statistical Yearbook, OECD, UNICEF and WHO were taken and comparisons were made among countries and regions of WHO, UNICEF and the World Bank (3, 5, 13-15). Some vital elements of the continuum of care in pre-pregnancy (contraceptive prevalence, unmet need for family planning, avoidable high-risk fertility behaviour), pregnancy (antenatal care coverage), birth (delivering in health facility, skilled attendant at birth, proportion of caesarean section), postnatal (initiation of breastfeeding, exclusive breastfeeding for 6 months, fully vaccinated, malnourished) periods (6) were selected and changes in frequency of the elements between 1993 and 2008 were calculated from TDHS (8-12). 


\section{RESULTS}

\section{Levels and Trends in Infant and Child Mortality in Turkey}

Under-five mortality rate during the five years preceding TDHS - 2008 was 24 per 1,000 live births (8). However, one in 10 children born in Turkey died before reaching the fifth birthday in 1988 (12). Table 1 shows declines in mortality rates from the findings of five TDHS since 1988. Neonatal mortality rates (NMR), post-neonatal mortality rates (PNMR), infant mortality rates (IMR), and under-five mortality rates (U5MR) were reduced from 1988 to 2008 by $63 \%, 92 \%, 79 \%$, and $76 \%$, respectively. Recent encouraging trends indicate an acceleration of decline since 1998 (8-12). In addition, in 2010, TURKSTAT declared IMR as $12.1 \%$ from data based on the 2008 Address Based Population Registration System (13). According to data of the Ministry of Health General Directorate of Maternal Child Health and Family Planning, the Health Statistical Yearbook-2010 reported that U5MR was $13.0 \%$, IMR 10.0\%o and NMR 8.5\% (3).

In Turkey, annual mean rate of decline in U5MR between 1990 and 2010 based on data of the World Health Statistics-2011 is 7.5\% (5). It is more than that of European Region of WHO (4.3\%), upper middle income group (4.5\%) and the world (2.2\%). Turkey is the 5th country showing large reductions in U5MR between 1990 and 2010 in data of The State of World Children following Maldives (annual mean rate of reduction: 9.6\%), San Marino (9.0\%), Oman (8.3\%), and Liechtenstein (8.0\%) (5). According to 2010 data, the Under-Five Mortality Rank of Turkey is 108 in descending order of estimated U5MR in countries, however, the rank was 61 in 1990, 71 in 1995 and 78 in 2002 (15-18).

All OECD countries have achieved remarkable progress in reducing IMR since 1970 (13). Since 1970, annual reduction in IMR has been $4.5 \%$ per year on average. During the same period, large reductions in IMR have been observed in Portugal (6.8\%), Korea (6.3\%), Israel (6.0\%), and Turkey (6.0\%). However, IMR in Turkey remains higher than the OECD average of $4.4 \%$ and Turkey was the 7th OECD country with the highest IMR after India, South Africa, Indonesia, Brazil, Mexico, and China - data obtained from a System of Health Accounts by OECD in 2009 (13).
Neonatal deaths constituted a much higher proportion of infant mortality and under-five mortality in Turkey since TDHS-1993 as well as in developed countries (Table 1). In addition, the risk of dying in the first month of life $(13 \%)$ is nearly three times higher than in the subsequent 11 months (4\%). The Data of World Health Statistics-2011 showed that neonatal mortality constituted $60 \%$ of U5MR in Turkey, 54\% in European Region, 50\% in upper middle income group, and $40 \%$ in the world (19). Turkey is a part of Millennium Development Goal regions in Western Asia. Similarly, in Western Asia region, neonatal deaths as a share of under-five deaths increased from $43 \%$ in 1990 to $48 \%$ in 2010 (5). Therefore, reducing child mortality depends upon tackling neonatal mortality in these regions.

The perinatal mortality rate for the five year period preceding TDHS-2008 was 19 per 1,000 pregnancies of seven or more month's duration (stillbirths and live births) (8). Comparable data from TDHS-2003 suggest that perinatal mortality was 24 per 1,000 (8) showing $21 \%$ reduction (Table 1 ).

\section{Some Differentials in Child Mortality in Turkey}

The TDHS-2008 data pointed out some differences in infant and child mortality (8). Higher order births $(\geq 4)$ experienced elevated risks of mortality. Mortality rates for children born after a short interval ( $<2$ years) were found to have experienced mortality risks before their first birthdays higher than those in children born after an interval of 3 years or more. Age of mother at birth showed the expected U-shaped relationship with NMR, IMR and U5MR; higher mortality rates in younger $(<20$ years of age) and older maternal age ( $\geq 40$ years of age). The educational level of mother was inversely related to her child risk of dying. All childhood mortality rates, except for CMR, were the lowest for those in the highest wealth quintile. U5MR and IMR in the lowest two wealth quintiles were approximately two times higher than that in other three wealth quintiles. NMR, PNMR, IMR, CMR, and U5MR in rural areas were approximately 1.5 times higher than those in urban areas. Mortality rates changed by region; the East region had the highest mortality rates. In addition, children reported by mothers as "small or very small" at birth were at more than twice as high risk of dying compared to

Table 1. Changes in mortality rates in TDHS-2008, TDHS-2003, TDHS-1998, TDHS-1993 and TPHS-1988

\begin{tabular}{|c|c|c|c|c|c|c|c|c|c|c|}
\hline \multirow{2}{*}{$\begin{array}{l}\text { Mortality rates, } 1,000 \text { live } \\
\text { births }\end{array}$} & \multicolumn{5}{|c|}{ Turkish demographic health surveys } & \multicolumn{5}{|c|}{ Reduction in mortality rates (\%) } \\
\hline & $\begin{array}{l}\text { TPHS } \\
1988 \\
\end{array}$ & $\begin{array}{c}\text { TDHS } \\
1993\end{array}$ & $\begin{array}{c}\text { TDHS } \\
1998\end{array}$ & $\begin{array}{l}\text { TDHS } \\
2003\end{array}$ & $\begin{array}{l}\text { TDHS } \\
2008\end{array}$ & 1988-1993 & 1993-1998 & 1998-2003 & 2003-2008 & 1988-2008 \\
\hline Under-five mortality rates & 98 & 61 & 52 & 37 & 24 & 38 & 15 & 29 & 35 & 76 \\
\hline Child mortality rates & 17 & 9 & 10 & 9 & 6 & 47 & -11 & 10 & 33 & 65 \\
\hline Infant mortality rates & 82 & 53 & 43 & 29 & 17 & 35 & 19 & 33 & 41 & 79 \\
\hline Post neonatal mortality rates & 48 & 23 & 17 & 12 & 4 & 52 & 26 & 29 & 67 & 92 \\
\hline Neonatal mortality rates & 35 & 29 & 26 & 17 & 13 & 17 & 10 & 35 & 24 & 63 \\
\hline $\begin{array}{l}\text { Perinatal mortality rates, } \\
1,000 \text { pregnancies }\end{array}$ & ND & ND & ND & 24 & 19 & ND & ND & ND & 21 & ND \\
\hline $\begin{array}{l}\text { The proportion of neonatal } \\
\text { mortality in under-five } \\
\text { mortality (\%) }\end{array}$ & 35 & 47 & 49 & 45 & 57 & & & & & \\
\hline $\begin{array}{l}\text { The proportion of neonatal } \\
\text { mortality in infant mortality (\%) }\end{array}$ & 43 & 55 & 60 & 59 & 76 & & & & & \\
\hline
\end{tabular}

TDHS: Turkish Demographic Health Survey, TPHS: Turkish Population Health Survey, ND: no data. 
children whose birth weight was reported as being "average or larger than average" (8).

Child mortaliy indices (CMI) were 0.76 in TDHS-1993, 0.69 in TDHS-2003 (20). As expected, CMI was higher in cases with lower maternal education, absence of parental health insurance, younger-older maternal age at delivery, high birth order, maternal smoking, the lack of access to safe drinking water and poor sanitation facility, delivering at home, absence of antenatal care, incomplete vaccination, rural residence, the East region, the lowest wealth quintile. However, presence of consanquinity, extended family and absence of civil marriage were also reported to be special determinants of CMI in Turkey (20).

\section{Health Care System in Turkey}

The Ministry of Health is officially responsible for designing and implementing health policies and delivering health-care services nationwide and for the implementation of curative and preventive health-care services throughout the country. The responsibility for implementing specific Primary Health Care Programmes was shared by various General Directorates (Primary Health Care, Maternal and Child Health and Family Planning, Therapeutic Services, Health Education). In 1990, the Ministry of Health planned the National Health Policy targets that focused on infant, child and maternal mortality. In 2003, the Health Transformation Programme was launched in Turkey, and the major goal of this programme was to organize, finance and deliver health care services in the effective and efficient way in conformity with equity policy in order to reduce health disparities, increase equity, access and improve the quality of health care and reduce its fragmentation $(2,4,21,22)$.

The strategic approach to improve maternal and perinatal health supports the continuum of care during pregnancy, childbirth and the postpartum period for mothers and newborn babies, including national access to cost-effective interventions and a functioning referral system and regionalization of perinatal care $(1,6,7,23,24)$. As seen in Table 2, several package interventions for mothers and children were implemented to combat child mortality in Turkey so that every child receives the continuum of care prenatally through childhood $(2,21,22,25)$.

\section{Continuum of Care in Turkey \\ Pre-pregnancy: Need for Family Planning}

In order to decrease infant mortality, reachable reproductive health care services are necessary $(6,22,24)$. The Turkish Sexual and Reproductive Health Programme was implemented in cooperation with the European Union in order to increase the utilization and accessibility of services in the field of sexual and reproductive health as well as to support studies conducted by the Ministry of Health and strengthen collaboration with the non-governmental organizations (NGOs) $(2,21,22)$. In addition to health care services, the Ministry of Health and Turkish Armed Forces collaborated on trainings on reproductive health and family planning offered to male population (Table 2).

As seen in Table 3, the modern contraceptive use rose over the last 15 year period, from $34.5 \%$ to $46.0 \%$. The total demand for family planning among currently married women aged 15-49 years is $79 \%$ and $92 \%$ of this demand is satisfied (8), however, the percentage of unmet need for family planning remained virtually unchanged between 2003 and 2008 (6.0\% and 6.2\%, respectively).

In Turkey, the high risk fertility (mothers' age $<18$ or $>34$, or birth interval $<24$ months or birth order $>3$ ) rates decreased by $21.0 \%$ since 1993 (Table 3). The number of "too young" mothers $(<18$ years of age) decreased from $4.1 \%$ in 1993 to $2.7 \%$ in $2008(8,11)$.

\section{Pregnancy: Antenatal Care (ANC)}

The Ministry of Health have started to provide free of charge iron supplementation to pregnant women to protect them and their babies from anaemia (Table 2). Regardless of the ANC status, $80 \%$ of them reported receiving iron tablets in TDHS-2008 (8).

The Conditional Cash Transfer Programme Health Scheme has been implemented in Turkey to alleviate the burden of child care expenses in low-income mothers since 2003 (Table 2). In people with the lowest income, who constitute the poorest $6 \%$ of entire population, pregnant women are granted monthly allowance if they continue to visit health institutions for check-ups $(4,21)$.

The proportion of women attending ANC in Turkey increased dramatically from the TDHS-1993 period to the TDHS-2008 period (Table 3). In 2008, 92\% of women reported at least one ANC visit and $73.7 \%$ four and more ANC visits (8). In 2000, the mean ANC was 1.7 and increased to 4.2 in 2010 (3).

The effectiveness of ANC in ensuring safe motherhood depends in part on tests and measurements done during the check-ups to detect potential complications. Among women receiving antenatal care, $92 \%$ had their blood pressure measured, $96 \%$ of women had ultrasound, $83 \%$ had their weight measured, in $82 \%$ of women urine analysis and $86 \%$ blood analysis were performed. Overall, the levels of all examinations in ANC reported in TDHS-2008 are notably higher than the levels reported in TDHS-2003 $(8,9)$.

Maternal smoking affects their children's health in terms of vulnerability to respiratory illness and increases the risk of having a low birth weight (LBW) baby. According to the TDHS-2003 data, $15.0 \%$ of pregnant women and $19.6 \%$ of breastfeeding women were currently smoking, however, in TDHS-2008 the numbers decreased to $11.4 \%$ and $16.5 \%$, respectively $(8,9)$.

\section{Delivery and Postnatal Care}

One indicator for monitoring progress of the MDG target 5A (the maternal mortality ratio) was the proportion of births attended by skilled health personnel (1). Given high costs and high risks of sick newborns referral, women who might encounter complication related to pregnancy, are referred as soon as possible to a health facility which have the necessary skilled health professionals and the necessary equipment of the Emergency Obstetric Care Programme $(2,21,22,25)$. As recommended in this programme, risk caring pregnant women living in rural areas where might be problems during transportation to the health center, have been hospitalized from the last trimester to delivery (Table 2). Pregnants are granted monetary aid under the Conditional Cash Transfer Programme for people with the lowest income when they give birth at public hospitals (Table 2). Also, mothers are paid monthly for each child aged $0-6$, provided that children undergo health check ups regularly (2). Therefore, the proportion of newborns born in health facilities increased from $49.7 \%$ in TDHS-1993 to $89.7 \%$ in the TDHS-2008 period (Table 3 ). In TDHS-2008, $89.7 \%$ of all births in the five years preceding the survey were 


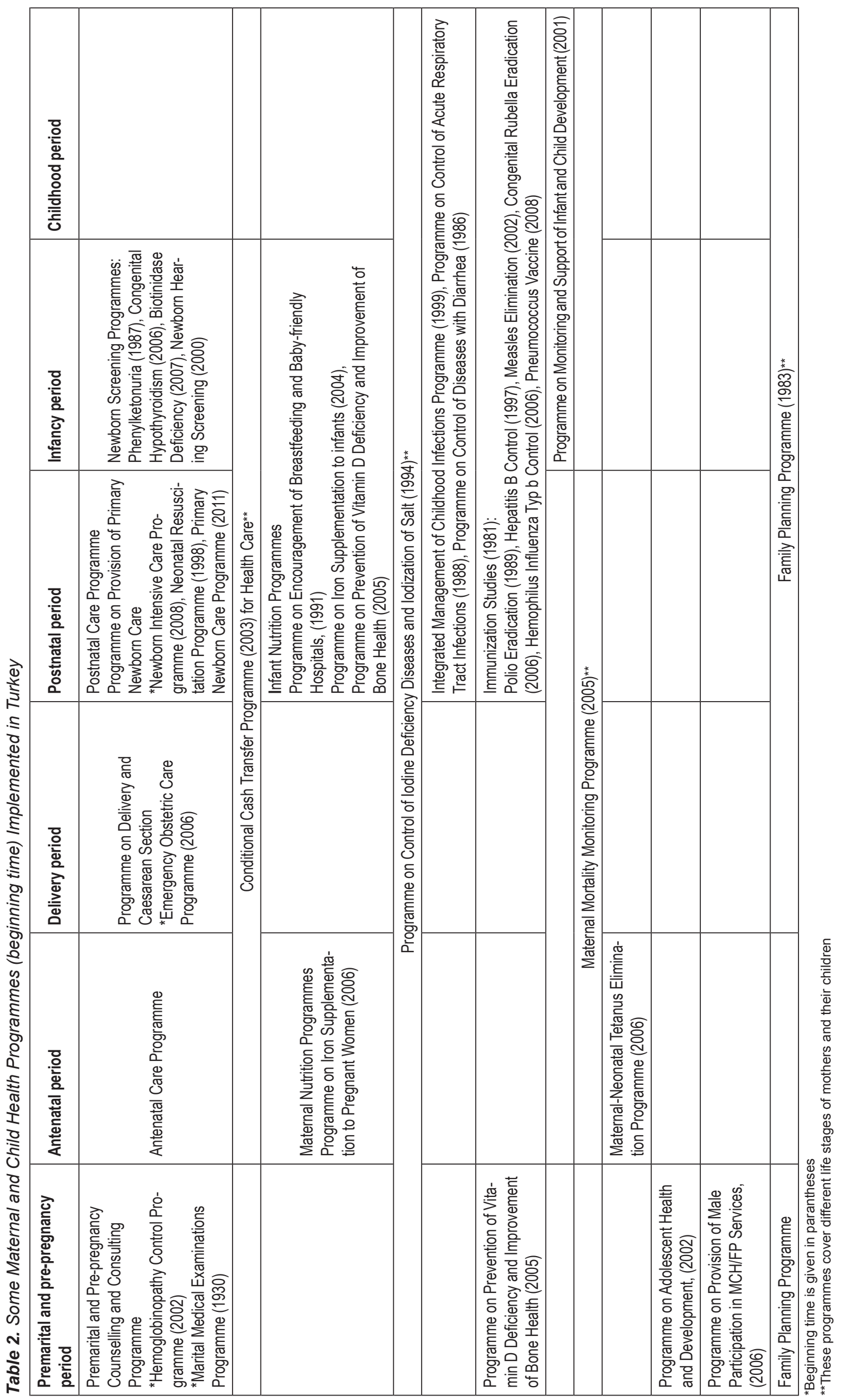


Table 3. Changes in the prevalences of some parameters of the continuum of care in Turkey

\begin{tabular}{|c|c|c|c|c|c|c|c|c|}
\hline & \multicolumn{4}{|c|}{ Turkish demoghrapic health survey (\%) } & \multicolumn{4}{|c|}{ Changes in prevalence (\%) } \\
\hline & $\begin{array}{l}\text { TDHS } \\
1993\end{array}$ & $\begin{array}{l}\text { TDHS } \\
1998\end{array}$ & $\begin{array}{l}\text { TDHS } \\
2003\end{array}$ & $\begin{array}{l}\text { TDHS } \\
2008\end{array}$ & 1993-1998 & 1998-2003 & 2003-2008 & $1993-2008$ \\
\hline \multicolumn{9}{|l|}{ Pre-pregnancy } \\
\hline $\begin{array}{l}\text { Any modern contraceptive } \\
\text { method }\end{array}$ & 34.5 & 37.7 & 42.5 & 46 & 9.3 & 12.7 & 8.2 & 33.3 \\
\hline $\begin{array}{l}\text { Any traditional or modern } \\
\text { contraceptive method }\end{array}$ & 62.6 & 63.9 & 71 & 73 & 2.1 & 11.1 & 2.8 & 16.6 \\
\hline $\begin{array}{l}\text { Unmet need for family } \\
\text { planning }\end{array}$ & 12.0 & 10.1 & 6.0 & 6.2 & -15.8 & -40.6 & 3.3 & -48.3 \\
\hline $\begin{array}{l}\text { Avoidable high-risk fertility } \\
\text { behaviour** }\end{array}$ & 44.3 & 40.2 & 39 & 35 & -9.3 & -3.0 & -10.3 & -21.0 \\
\hline \multicolumn{9}{|l|}{ Pregnancy } \\
\hline $\begin{array}{l}\text { Antenatal care coverage } \\
\geq 1 \text { visit }\end{array}$ & 62.3 & 67.9 & 80.9 & 92 & 9.0 & 19.1 & 13.7 & 47.7 \\
\hline $\begin{array}{l}\text { Antenatal care coverage } \\
\geq 4 \text { visit }\end{array}$ & 35.9 & 42 & 53.9 & 73.7 & 17.0 & 28.3 & 36.7 & 105.3 \\
\hline \multicolumn{9}{|l|}{ Birth } \\
\hline Delivering in health facility & 59.9 & 72.5 & 78.2 & 89.7 & 21.0 & 7.9 & 14.7 & 49.7 \\
\hline Skilled attendant at birth & 75.9 & 80.6 & 82.9 & 91.3 & 6.2 & 2.9 & 10.1 & 20.3 \\
\hline Physician delivery rates & 33.7 & 40.1 & 46.7 & 64.1 & 19.0 & 16.5 & 37.3 & 90.2 \\
\hline $\begin{array}{l}\text { Proportion of caesarean } \\
\text { section in all births }\end{array}$ & ND & 13.9 & 21.2 & 36.7 & & 52.5 & 73.1 & \\
\hline \multicolumn{9}{|l|}{ Postnatal } \\
\hline $\begin{array}{l}\text { Early initiation } \\
\text { of breastfeeding } \\
\text { (within } 1 \text { hour of birth) }\end{array}$ & 19.9 & 51.8 & 53.9 & 39 & 160.3 & 4.1 & -27.6 & 96.0 \\
\hline $\begin{array}{l}\text { Initiation of breastfeeding, } \\
\text { first day }\end{array}$ & 75.9 & 84.8 & 83.6 & 73.4 & 11.7 & -1.4 & -12.2 & -3.3 \\
\hline $\begin{array}{l}\text { Exclusive breastfeeding for } \\
6 \text { months }\end{array}$ & 10.4 & 10.7 & 20.8 & 41.6 & 2.9 & 94.4 & 100.0 & 300.0 \\
\hline $\begin{array}{l}\text { Fully vaccinated (BCG, } \\
\text { measles, and three doses of } \\
\text { DPT and polio) }\end{array}$ & 64.7 & 45.7 & 54.2 & 80.5 & -29.4 & 18.6 & 48.5 & 24.4 \\
\hline No vaccination & 3.1 & 3.6 & 2.8 & 1.6 & 16.1 & -22.2 & -42.9 & -48.4 \\
\hline Low birth weight & ND & 7.9 & 7.9 & 11 & & 0.0 & 39.2 & \\
\hline Height for age $\leq 2$ y score & 18.9 & 16 & 12.2 & 10.3 & -15.3 & -23.8 & -15.6 & -45.5 \\
\hline Weight for height $\leq 2$ y score & 3 & 1.9 & 0.7 & 0.9 & -36.7 & -63.2 & 28.6 & -70.0 \\
\hline Weight for age $\leq 2$ y score & 9.5 & 8.3 & 3.9 & 2.8 & -12.6 & -53.0 & -28.2 & -70.5 \\
\hline
\end{tabular}

${ }^{*}$ Currently married fecund women who either want to postpone the next birth (need for spacing) or who want no more children (need for limiting), but who are not using a contraceptive method, are considered to have "unmet need" for family planning

${ }^{* *}$ Avoidable high risk behaviour includes "Mothers's age $<18$ or $>34$ " or "Birth interval $<24$ months" or "Birth order $>3$ "

ND: no data, TDHS: Turkish Demographic Health Survey

delivered at a health facility (8). In particular, physician-attended deliveries rapidly increased from $33.7 \%$ in TDHS- 1993 to $64.1 \%$ in TDHS-2008, an increase of over $90.2 \%$. On the other hand, the caesarean delivery rate increased from $13.9 \%$ in TDHS-1998 to $36.7 \%$ in TDHS-2008 (Table 3).

In TDHS-2008 survey, $81.7 \%$ of women reported that they had a postnatal check-up provided by a doctor/nurse/midwife and $63.4 \%$ received this care within the first four hours after delivery. On the other hand, $15.5 \%$ did not receive any care after the delivery of their last live birth (8).
An important component of detecting anomalies and risks in neonates that may help prevent mortality is a thorough newborn examination (6). Approximately $88.0 \%$ of infants received postnatal care from health personnel and $11.1 \%$ declared no postnatal visit in TDHS-2008 (8). With respect to the timing of the first postnatal care visit, $66.6 \%$ of newborns have the first checkup within four hours after delivery and $74 \%$ within the first day of life following delivery. The mean postnatal care for infants was 3.2 in 2000 and 7.1 in 2010. Similarly, the mean visit for children was 1.0 in 2000 and 1.6 in 2010 (3). 


\section{Infancy \\ Breastfeeding}

In 1991, the Promotion of Breastfeeding and Baby Friendly Hospitals Programme was implemented in four participating hospitals to encourage, protect, promote, and support the use of breast milk in baby nutrition. The number of hospitals participating in the Baby Friendly Programme increased to 141 by 2002, and to 784 by 2010. In 2002, 21\% of deliveries took place in Baby Friendly Hospitals while this proportion increased to $92 \%$ in 2010. After 2000, the Baby Friendly Cities Programmes developed and 78 cities were awarded this title in 2010 and 31 of them were titled Golden Baby Friendly Cities $(21,25)$. In Turkey, breastfeeding is traditional, $97 \%$ of children are breastfed for some period of time (8). The median duration of breastfeeding for all children increased from 11.9 months in TDHS-1993, 12 months in TDHS-1998, 14.9 months in TDHS-2003 to 16 months in TDHS-2008 $(8,11)$. Early initiation of breastfeeding within the first hour of delivery was $19.9 \%$ in $1993,51.8 \%$ in $1998,53.9 \%$ in 2003 , and $39.0 \%$ in 2008 . As a result of this programme, the percentage of babies under 6 months fed only with breastmilk (exclusive breastfeeding) increased to 41.6 in 2008 from 10.4 in 1993 (Table 3).

\section{Childhood Vaccination Coverage}

With stable and well-funded primary health care systems for vaccination in Turkey (Table 2), rates of full vaccination coverage against tuberculosis, diphtheria, pertussis, tetanus, poliomyelitis, and measles increased from $45.7 \%$ to $80.5 \%$ between 1998 and 2008 (Table 3). In TDHS-2008, very few children aged 15-26 months $(<2 \%)$ are reported not being fully vaccinated (8). Turkey was declared polio-free by WHO in 2002 (21, 25). In February 2009 , following the validation efforts made in consultation with WHO, Turkey taken place among the countries eliminating maternal and neonatal tetanus (21). To stop the domestic measles virus circulation in Turkey by the end of 2010, a wide measles vaccination campaign was launched in 2003-2005 covering children aged 1-14 years. The vaccination coverage of campaign was 97\%. Then, the National Vaccination Programme was changed in 2006, and two doses of measles-mumps-rubella vaccine were provided to infants and children at 12 months and 6 years of age. From 2008-2010, vaccination rate of measles-mumps-rubella was $97 \%$ countrywide, reaching official target of the MDG 4 indicator on measles vaccination coverage $\geq 95 \%(3,21)$. As a result, the number of measles cases in Turkey decreased dramatically from the early 2000s. The number of measles cases decreased dramatically from 30,509 in 2001 to 7,810 in 2002, 34 in 2006, 3 in 2007, and no local cases reported between 2008 and 2010 (3). Hemophilus influenza type b (Hib) vaccinations started in 2006 and conjugated pneumococcus vaccine (PCV) in 2008. Five-item combined vaccine (diphteria-acellular pertussis-tetanus-Hibinactive polio vaccine) has been given since 2008. In 2010, the third dose immunization coverage of five-item combined vaccine, HBV and PCV was 97\%, 96\% and 95\%, respectively (3).

\section{Diarrheal Diseases}

In Turkey, the National Control of Diarrheal Diseases Programme was established in 1986 with the objective to reduce child deaths due to dehydration $(2,21,22)$. Overall, $23.3 \%$ of children had experienced diarrhea in the last two weeks preced- ing THDS-2008, similarly, it was 24.8\% in TDHS-1993 $(8,11)$. However, $47.0 \%$ of children with diarrhea were taken to a health provider in TDHS-2008, compared to $24.8 \%$ in TDHS-1993.

The proportion of population with access to safe drinking water to total population was $97.8 \%$ in 2008 (99.9\% in urban areas, 93\% in rural areas), 83.1\% in 1994 (96.1\% in urban areas, $68 \%$ in rural areas) (4). The proportion of population using an improved sanitation facility was $89.5 \%$ (96.1\% in urban areas, $74.5 \%$ in rural areas) in 2008 , whereas it was only $67.4 \%(85.7 \%$ in urban areas, $46.3 \%$ in rural areas) in 1994.

\section{Nutritional Status of Children}

TDHS-2008 survey reported $10.3 \%$ of children under age 5 were stunted, $2.8 \%$ underweight and $0.9 \%$ wasted (8). Stunting rates has decreased by $45.5 \%$ and underweight rates by $70.0 \%$ in 15 years (Table 3). On the other hand, the low birth weight (LBW, weighed less than 2,500 grams at birth) rate increased from $7.9 \%$ to $11 \%$ between TDHS-2003 and TDHS-2008. Increase in the rates of caesarean delivery in the last decades might play a role in this change (Table 2). In 2009 in OECD countries, one in fifteen babies ( $6.7 \%$ of all births) was LBW born (13). Alongside a number of emerging countries (India, 27.6\%; South Africa, $12.3 \%$; and Indonesia, 11.1\%), Turkey is at the other end of the scale, with the rate of LBW infants above $10 \%$.

\section{Micronutrient Supplementation}

In our country, some interventions including micronutrient supplementation with iron and vitamin D in infants, iron and folate in pregnant women and universal promotion of iodized salt (Table 2) have been implemented $(2,21,25)$. In 2004, the Iron-Like Turkey Programme was implemented in order to increase awareness in the society about anaemia, ensure exclusive breastfeeding for the first six months, continuation of breastfeeding until the age of 2 together with convenient supplementary food, ensure iron support between 4-12 months for all babies, and iron treatment for 13-24 months old babies with anaemia. In 2007, the research on iron deficiency was conducted in order to detect the impact of the programme. The anaemia prevalence in children aged 12-23 months decreased to $7.8 \%$ (26).

\section{Neonatal Screening Programmes}

Neonatal Phenylketonuria Screening Programmes started in 22 cities at 1987, and then were extended to the whole country. The Congenital Hypothyroidism Screening Programme was initiated in 2006, the Biotinidase Deficiency Screening Programme in 2008. The neonatal screening rate was $52.7 \%$ in 1998 , however, increased to $88 \%$ in 2007 , and it was higher than $95 \%$ in the period from 2008-2010 (21, 25).

\section{Neonatal Problems}

The Infant Mortality Monitoring Programme started to detect the leading causes of death in Turkey in 2007. Between 2007 and 2009, the most significant causes of neonatal mortality were found to be preterm birth (30\%), congenital anomaly (16\%), infections (14\%), and asphyxia (6\%) (2). The Neonatal Intensive Care Programme was implemented in 1998 (Table 2). A total of 32,282 health personnel have been trained until the end of 2009 . Nowadays, all hospitals where deliveries are made have staff who attended a Newborn Resuscitation Training. From 2002 to 2010, 
also the provision of equipment improved; the number of newborn intensive care beds increased from 665 to 2,544, transport incubators from 158 to 540 and ventilators from 252 to $684(3,21,25)$.

\section{Maternal Mortality}

In 1973, maternal mortality in Turkey was eight times higher than the average in OECD countries, then, between 1973 and 2007, maternal mortality fell steeply, by about ten-fold (27). As a result, in 2007, maternal mortality in Turkey was 2.5 times higher than the OECD average. The Maternal Mortality Monitoring Programme has been implemented since 2006. The maternal mortality rate declined from $28.5 / 100,000$ in 2006 to $16.4 / 100,000$ in $2010(2,3,21)$.

\section{Maternal Education}

The TDHS-2008 and TDHS-2003 results indicate that the mother's level of education is inversely related to her child's risk of dying and the largest decrease in mortality rates according to mother's education occurred especially in the postneonatal period $(8,9)$. This pattern is expected because education exposes mothers to information about better nutrition, use of contraception to limit and space births, health care during pregnancy, and childhood illnesses, vaccinations, and treatments, all of which contribute to lower mortality risks in children $(8,9)$.

The primary education ( 5 years for primary level; 3 years for secondary level) is considered the basic education, starts at the age of 6 and has been compulsory since 1997. An examination of changes in educational attainment by successive age groups indicates that there has been a marked improvement in the educational attainment of both men and women in Turkey; the median number of years of schooling among the 20-24 year age groups (10.4 for males and 7.6 years for females) is higher than that among the 40-44 age group (5.0 for males and 4.5 years for females) in TDHS-2008 (8). The Gender Parity Indices, which represents the ratio of the net attendance ratios for females to that for males are 0.98 for primary school and 0.83 for high school, respectively, in TDHS-2008 compared to the values 0.92 and 0.78 in TDHS-2003 $(8,9)$.

\section{Poverty}

In further analysis of TDHS-2003, it was detected that children of poorest households experienced 4.7 times higher risk of dying before completing their first birthday and 3.5 times higher risk of dying before completing their fifth year of life compared to children from the richest households (28). The proportion of the population subsisting on less than $2.15 \$$ per day was reduced from $3.04 \%$ in 2002 to $0.22 \%$ in 2009 , however, the rate of poor individuals with relative poverty based on expenditure was still high in Turkey; 14.7\% in 2002 and 15.1\% in 2009 (14).

Health spending tends to rise with income: in general, OECD countries with higher GDP per capita tend to spend more on health. Total health spending accounted for $6.1 \%$ of GDP in Turkey, below the average of $9.6 \%$ across OECD countries in 2009 (27).

The Human Development Index was a composite index measuring average achievement in three basic dimensions of human development, calculated by life expectancy at birth, mean years of schooling, expected years of schooling, and the gross national income. In 2011, the HDI value of Turkey was 0.699 and HDI rank was 92 out of 187 countries (29).

\section{DISCUSSION}

Looking at the past 20 years, significant strides have been made in child survival (Table 1, Table 3). Specifically, U5MR has dropped by more than $75 \%$ for the last 20 years but there is still a long way to go. Despite these achievements, some populations remain at high risk for NMR, IMR and U5MR mortality, namely: residents of the East region, rural residents, falling into the lowest quintile of wealth, with younger mother at birth, low level of maternal education, high-birth order, short birth intervals, and low birth weight. There is also an unmet need for family planning which remained virtually unchanged during the last decade (Table 3). Programmes and action plans for prevention of marriage between relatives and promotion of civil marriages might also improve U5MR in Turkey. Also, encouraging long families (mothers with high parity) to adopt family planning will decrease both mortality rates of children and mothers in our country. In addition, interventions are necessary to decrease caesarean section rates and smoking.

A rapid increase in antenatal care attendance and in the proportion of women delivering in health institutions and the rapid development of neonatal intensive care, improvement in maternal education and impressive expansion of public health programmes in Turkey all directly contributed to increased survival of newborns and children. The decrease in the number of adolescents giving birth might also reduce the risk of infant mortality. In addition, the major improvements in coverage of Hib and PCV vaccinations, and further progress on measles, mumps, rubella vaccinations and iron supplementation might not yet be fully reflected in these mortality data. Therefore, there is a reason to believe that the acceleration in child survival might already be well under way in Turkey.

The effort to combat child mortality should focused on strengthen community partnerships and health systems that can provide preventive care. Estimating the need for maternal and newborn health services is straightforward: access to the continuum of care should be guaranteed for all women and their infants.

\section{Conflicts of Interest}

None declared

\section{Acknowledgments}

This study was supported by HTSSRP/TUSAK/2009/INDIVIDUAL/ IC/37-Reduction in Child Mortality Project. We are grateful to Prof. Dr. Recep Akdağ (the Minister of Health of Turkey), Prof. Dr. Nihat Tosun (the Ministry of Health of Turkey), Mustafa Kosdak, Dr. Zekiye Çipil and Dr. Feray Esenyel (Deputy Manager of School of Public Health, Refik Saydam Hygiene Center Presidency), and Dr. Sema Özbaş (Deputy Manager, the Ministry of Health, General Directorate of Maternal Child Health and Family Planning,) for providing technical support to access health data. 


\section{REFERENCES}

1. WHO Regional Office for Europe. Millennium development goals in the WHO European region: a situational analysis at the eve of the five-year countdown. Copenhagen: WHO Regional Office for Europe; 2010.

2. Jelamschi L, De Ver Dye T. Decline in the under 5 mortality rate (U5MR) in Turkey: a case study. 2010. Ankara: UNICEF Turkey; 2010.

3. Mollahaliloğlu S, Bora Başara B, Eryilmaz Z, editors. Health Statistics Yearbook 2010. Ankara: Republic of Turkey, Ministry of Health, Refik Saydam Hygiene Center Presidency, School of Public Health; 2011.

4. Alata S, Arslan HM, Bayazit Baran B, Duman N, editors. Millennium development goals report Turkey 2010. Ankara: the Office of the United Nations Resident Coordinator; 2010.

5. You D, Jones G, Wardlaw T, editors. Levels \& trends in child mortality. Report 2011. Estimates developed by the UN Inter-agency group for child mortality estimation. New York: United Nations Children's Fund (UNICEF); 2011.

6. Moccia P, editor. The state of world's children 2009: maternal and newborn health. New York: : United Nations Children's Fund (UNICEF); 2008.

7. Lazarus JV, Bjørk C, Østergren M. Improving family and community health in Eastern Europe - the lifecycle approach at WHO. Cent Eur J Public Health. 2006 Sep;14(3):109-12.

8. Hacettepe University Institute of Population Studies. Turkey. Demographic and health survey, 2008. Ankara: HUIPS, Ministry of Health General Directorate of Mother and Child Health and Family Planning, T.R. Prime Ministry Undersecretary of State Planning Organization and TUBITAK; 2009.

9. Hacettepe University Institute of Population Studies. Turkey. Demographic and health survey 2003. Ankara: HUIPS, Ministry of Health General Directorate of Mother and Child Health and Family Planning, State Planning Organization and European Union; 2004.

10. Hacettepe University Institute of Population Studies. Turkish Demographic and health survey 1998. Ankara: HUIPS, Ministry of Health General Directorate of Mother and Child Health and Family Planning, MEASURE DHS+, Macro International; 1999.

11. Hacettepe University Institute of Population Studies. Turkish Demographic and health survey 1993. Ankara: HUIPS, Ministry of Health General Directorate of Mother and Child Health and Family Planning, Macro International; 1994.

12. Hacettepe University Institute of Population Studies. Turkish population and health survey 1988. Ankara: HUIPS; 1989.

13. Health at a glance 2011: OECD indicators. Paris: OECD Publishing; 2011 .

14. Turkish Statistical Institute [Internet]. Ankara: TurkStat; 2013 [cited 2013 Feb 1]. Available from: http://www.tuik.gov.tr/.
15. Aslam A, Szczuka J, editors. The state of the world's children 2012: children in an urban world. New York: United Nations Children's Fund (UNICEF); 2012.

16. The state of the world's children 1992. New York: Oxford University Press; 1992.

17. The state of the world's children 1997: child labour. New York: Oxford University Press; 1997.

18. The state of the world's children 2004: girls, education and development. New York: United Nations Children's Fund (UNICEF); 2003.

19. World Health Organization. World health statistics 2011. Geneva: WHO; 2011

20. Yüksel I, Koç İ. Is the infant mortality rate stil a puzzle in Turkey? Çocuk Sağlığı ve Hastalıkları Dergisi. 2010;53(2):87-97. (In Turkish.)

21. Akdağ R, editor. Turkey health transformation program: evaluation report (2003-2010). Ankara: Republic of Turkey Ministry of Health; 2011.

22. Yardım N, Mollahaliloğlu S, Hülür U, et al. Turkey and 21 targets: future health. Ankara: Republic of Turkey, Ministry of Health, Refik Saydam Hygiene Center Presidency, School of Public Health; 2007. (In Turkish.)

23. Cavagnero E, Daelmans B, Gupta N, Scherpbier R, Shankar A Countdown; Working Group on Health Policy and Health Systems. Assessment of the health system and policy environment as a critical complement to tracking intervention coverage for maternal, newborn, and child health Lancet. 2008 Apr 12;371(9620):1284-93.

24. Requejo J, editor. Countdown to 2015 decade report (2000-2010): taking stock of maternal, newborn and child survival. Geneva: WHO; 2010.

25. Özbaş S, Tezel B, Aydın Ş, Bolat H, Köse MR. The situation of children's health in Turkey. Cocuk Sağlığı ve Hastalıkları Dergisi. 2012;55(2):71-6. (In Turkish.)

26. Yalcin SS, Pekcan G, Tezel B, et al. The survey report of iron usage in children aged 12-23 months. Ankara: Printing Office of General Directorate of Mother and Child Health and Family Planning, Ministry of Health; 2009. (In Turkish.)

27. OECD Reviews of health systems: Turkey. Paris: OECD Publishing; 2008.

28. Eryurt MA, Koç I. Poverty and child mortality: the effect of household wealth status on child mortality. Çocuk Sağlığı ve Hastalıkları Dergisi. 2009;52(3):113-21. (In Turkish.)

29. Human Development Report [Internet]. New York: Human Development Report Office; 2013. International human development indicators: Turkey; [cited 2013 Feb 1]. Available from: http://hdrstats.undp.org/en/ countries/profiles/TUR.html. 